\title{
Differentiated embryonic chondrocyte-expressed gene 1 is associated with hypoxia-inducible factor $1 a$ and Ki67 in human gastric cancer
}

Yan-Fei Jia ${ }^{1,2}$, Dong-Jie Xiao ${ }^{1}$, Xiao-Li Ma' ${ }^{1}$ Yan-Yan Song ${ }^{3}$, Rui Hu ${ }^{3}$, Yi Kong ${ }^{3}$, Yan Zheng ${ }^{1}$, Shu-Yi Han ${ }^{1}$, Ruan-Li Hong ${ }^{4}$ and Yun-Shan Wang ${ }^{1,2^{*}}$

\begin{abstract}
Background: Gastric cancer is a leading causes of cancer-related deaths, but the underlying molecular mechanisms of its progression are largely unknown. Differentiated embryonic chondrocyte-expressed gene 1 (DEC1), is an important transcription factor involved in the progression of tumors and has recently been identified to be strongly inducible by hypoxia. Little is known about the contribution of DEC1 to the intracellular hypoxia and proliferation signaling events in gastric cancer.

Methods: Immunohistochemistry was used to detect the expression of DEC1, hypoxia-inducible factor 1(HIF-1a) and Ki67 in 173 human gastric cancer samples and adjacent non-tumor tissues samples. The relationship between DEC1, HIF-1a and Ki67 was evaluated.

Results: DEC1 protein was persistently expressed in the nucleus and cytoplasm of gastric cancer tissue. The protein expression of DEC1 and HIF-1a in tumour tissues was $83.8 \%$ and $54.3 \%$, respectively, and was significantly higher than that in adjacent normal tissues (83.8\% vs $23.7 \%, \mathrm{P}<0.001 ; 54.3 \%$ vs $12.7 \%, \mathrm{P}<0.001)$. The expression of DEC1 and HIF-1a was associated with poor histological differentiation. $(P<0.01)$. Furthermore, DEC1 level was positively correlated with HIF-1a $(P<0.01, r=0.290)$ and Ki67 expression $(P<0.01, r=0.249)$.
\end{abstract}

Conclusion: The upregulation of DEC1 may play an important role in hypoxia regulation and cell proliferation in gastric cancer. The relevant molecular mechanism requires further investigation.

Virtual Slides: The virtual slide(s) for this article can be found here: http:/www.diagnosticpathology.diagnomx.eu/vs/ 1794565980889391

Keywords: Differentiated embryo chondrocyte 1, Hypoxia-inducible factor 1a, Proliferation, Gastric cancer, Immunohistochemistry

\footnotetext{
* Correspondence: sdjnwys@163.com

${ }^{1}$ Central Laboratory, Jinan Central Hospital Affiliated to Shandong University, Jinan 250013, Shandong Province, China

2Shandong Province Key Lab of Tumor Target Molecule, Jinan Central

Hospital Affiliated to Shandong University, Jinan 250013, Shandong Province,

China

Full list of author information is available at the end of the article
} 


\section{Background}

Human differentiated embryonic chondrocyte-expressed gene 1 (DEC1) (also known as Stra13/Bhlhb2/Sharp2) is a basic helix-loop-helix (bHLH) transcription factor. Although little is known about its function in human physiological and pathological processes, recent studies have shown that DEC1 is a hypoxia-induced gene involved in cell differentiation, proliferation, and apoptosis [1,2].

Miyazaki $\mathrm{K}$ et al. [3] identified the hypoxia response elements in the DEC1 promoter and found that the $\mathrm{DEC} 1$ gene is a direct target of hypoxia-inducible factor 1 (HIF-1). DEC1 may be a hypoxia-regulated gene, so its expression in human tumors may be a direct marker of tumor hypoxia. The association of the clinical value of DEC1 expression and HIF- $1 \alpha$, the endogenous marker of hypoxia, has not been reported for gastric cancer. The studies with cultured cell lines have revealed that DEC1 expression is associated with hypoxia and HIF- $1 \alpha$ protein expression, and blockage of the HIF- $1 \alpha$ protein led to reduced DEC1 expression [4].

The clinical progression of gastric cancer is rapid and is reflected by various proliferation markers. The role of DEC1 in cell proliferation is inconsistent. DEC1 inhibits apoptosis in human embryonic kidney 293 cells [5,6] and induces apoptosis in mouse fibroblast NIH3T3 cells [7]. In addition, DEC1 has pro-apoptotic properties in human breast cancer cells [8].The intracellular signaling events related to the role of DEC1 in gastric cancer have not been well established.

In this study, we used immunohistochemistry to evaluate the expression status and clinicopathological features of DEC1 and HIF- $1 \alpha$ in 173 human gastric cancer samples and its adjacent non-tumor tissues by immunohistochemistry. The associations between DEC1 and HIF- $1 \alpha$, and proliferation marker Ki67 were analyzed.

\section{Materials and methods Patients and samples}

Surgically resected gastric cancer specimens were collected from 173 patients (117 males) at Jinan Central Hospital Affiliated to Shandong University, China, January 2011 to June 2012. The mean age of the patients was 62 years (range 30-88 years). Among the 173 tumor samples, 53 were well or moderately differentiated and 120 were poorly differentiated. The formalin-fixed, paraffin-embedded samples were retrospectively and randomly selected from the files of the Department of Pathology after the protocol was approved by the local research ethics committee. All the samples were evaluated for diagnosis by 2 experienced pathologists for diagnosis. None of the patients had received chemotherapy or radiation therapy preoperatively.

\section{Immunohistochemistry}

The tissues were fixed in 10\% neutral buffered formalin for $12 \mathrm{~h}$ and were routinely processed. The paraffin wax- embedded tissue blocks were cut into 4- $\mu \mathrm{m}$-thick sections. The formalin-fixed, paraffin-embedded sections were heated at $60^{\circ} \mathrm{C}$ for $60 \mathrm{~min}$ and placed into xylene for deparaffinization and graded ethanol for rehydration, then washed in phosphate-buffered saline (PBS). The antigen retrieval involved the use of a prewarmed pressure cooker with a solution of antigen retrieval citrate buffer ( $\mathrm{pH}$ 6.8) for 3 min. Following de-pressurization, cold water was poured into the cooker for $10 \mathrm{~min}$, then sections were rinsed well in warm water. The sections were incubated in $3 \% \mathrm{H}_{2} \mathrm{O}_{2}$ in methanol for $10 \mathrm{~min}$, then washed 3 times with PBS and incubated with the primary antibodies rabbit polyclonal anti-DEC1 (1:50, Genetex, CA, USA), mouse monoclonal anti-HIF-1 $\alpha$ (1:50, Santa Cruz Biotechnology, CA, USA), or rabbit monoclonal anti-Ki67 (1:50, Cell Signaling Technology, MA, USA) overnight in a moist chamber at $4^{\circ} \mathrm{C}$. Following a final wash, the sections were incubated with secondary antibody (KIT-5010, Max Vision, Maixin.Bio, China); TBS-Tween20 was used in all dilutions and intervening rinses. The ections were allowed to develop in diaminobenzidine (DAB) for $5 \mathrm{~min}$, and then were counterstained with hematoxylin. The slides were viewed under a microscope. The sections incubated without primary antibody were negative controls included in each run.

\section{Immunohistochemical staining evaluation}

The assessment of DEC1, HIF- $1 \alpha$ was as previously described $[9,10]$, by percentage of stained tumor cells and staining intensity. We examined a minimum of 3 different high-power $(\times 400)$ fields of tumor infiltration. The percentage of positive tumor cells was rated as follows: 0 , staining in $\leq 10 \%$ of tumor cells; $1+$, weak staining in $>10 \%$ of cells; $2+$, moderate staining in $>10 \%$ of cells; $3+$, strong moderate staining in $>10 \%$ of cells. Tumors scored as $3+/ 2+$ were positive cases; tumors scored as $0 / 1+$ were designated as negative cases. The Ki67 scoring system was 0 assigned for no cells staining positively; 1 for $\leq 10 \%$ of cells staining positively; 2 for $>10 \%$ of cells staining positively. The tumors scored as $3+/ 2+$ were positive cases; the tumors scored as $0 / 1+$ were designated as negative cases. Expression was analyzed by 2 independent investigators who used a multiheaded microscope and were blinded to the clinical data with consensus.

\section{Statistical analysis}

The statistical analysis used SPSS v11.5 (SPSS Inc., Chicago, IL). A chi-square test was used to test the association of DEC1 and HIF- $1 \alpha$ expression and the clinicopathological variables. The spearman correlation analysis was used to assess the correlation between DEC1 expression and HIF-1 $\alpha$ and Ki67 expression. $P<0.05$ was considered statistically significant. 
Table 1 Expression of differentiated embryo chondrocyte 1 and hypoxia-inducible factor 1a protein in gastric cancer and adjacent non-tumor tissues $\mathbf{n}(\%)$

\begin{tabular}{llllll}
\hline & Cases & DEC1 protein & & \multicolumn{2}{l}{ HIF-1a protein } \\
\cline { 3 - 5 } & & Positive & P value & & Positive \\
\hline Gastric cancer & 173 & $145(83.8 \%)$ & 0.000 & $94(54.3 \%)$ & P value \\
Adjacent non-tumor tissues & 173 & $41(23.7 \%)$ & & $22(12.7 \%)$ \\
\hline
\end{tabular}

DEC1 Differentiated embryo chondrocyte 1, HIF-1a Hypoxia-inducible factor-1.

\section{Results}

Expression of DEC1 and HIF-1a in gastric cancer and adjacent non-tumour tissues

DEC1 protein expression was located in the nucleus and cytoplasm of gastric cancer cells and was diffuse in 145 of 173 specimens (83.8\%; Table 1, Figure 1A and B). Compared with the gastric cancer tissue, the adjacent non-tumour tissues showed reduced DEC1 expression (23.7\%, P <0.001), with only cytoplasmic positive staining. The proportion of positive DEC1 nuclear and/or cytoplasmic staining in well and moderately differentiated tissues was 67.9\% (36/53) and in poorly differentiated tissues $90.8 \%$ (109/120), with a significant difference found between the two. The total DEC1 protein staining was associated with poorly differentiated
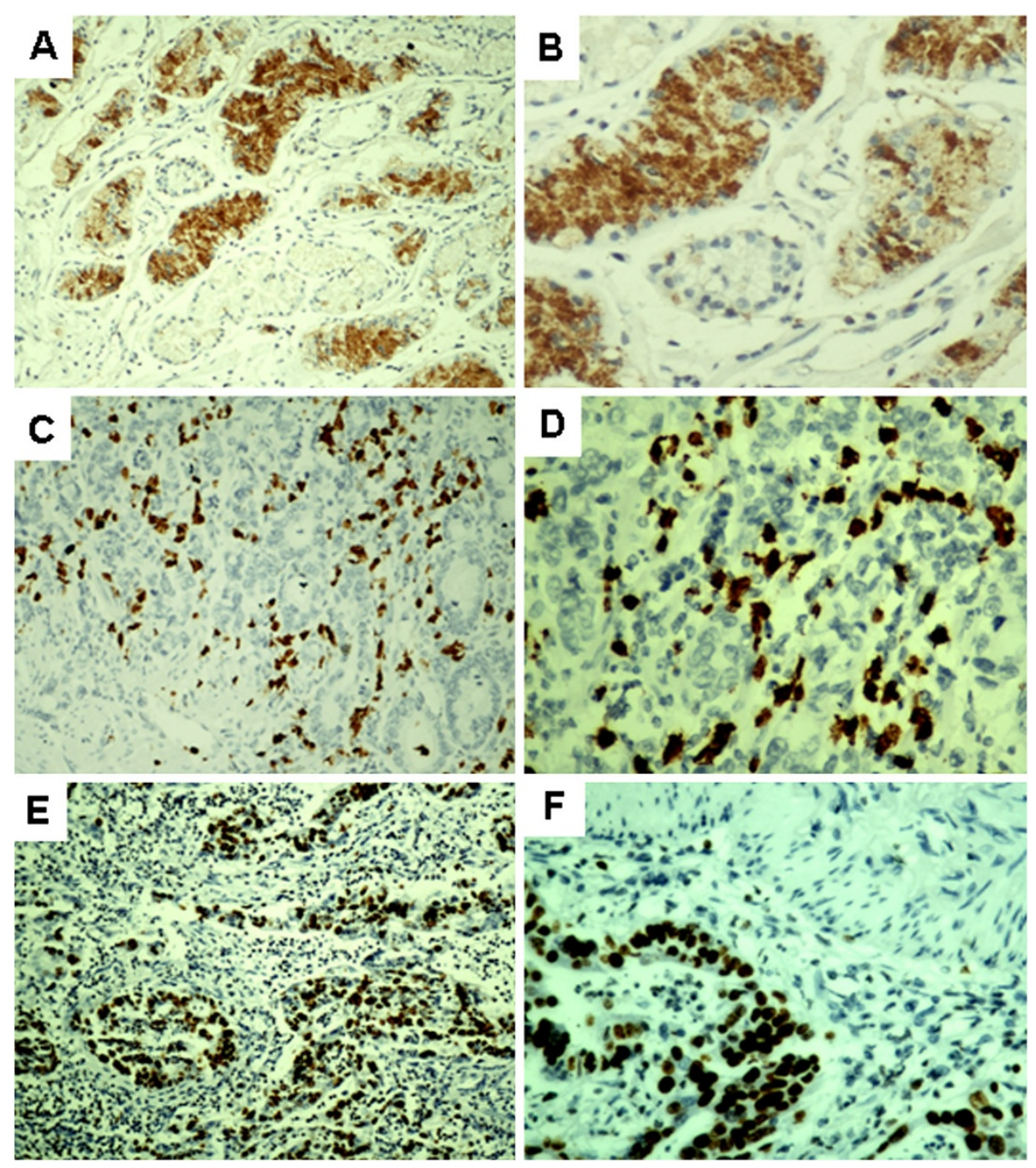

Figure 1 Expression of differentiated embryonic chondrocyte-expressed gene 1 (DEC1), hypoxia-inducible factor 1a (HIF-1a) and Ki67 protein in human gastric cancer tissue. Brown shows positive expression. Poorly differentiated gastric cancer with nuclear and cytoplasmic staining for DEC1 (A: SP, $\times 100$; B: SP, $\times 400)$. Poorly differentiated gastric cancer with nuclear staining for HIF-1a (C: SP, $\times 100 ; \mathbf{D}: S P, \times 400)$. Poorly differentiated gastric cancer with nuclear staining for Ki67 (E: SP, $\times 100$; F: SP, $\times 400$ ). 
Table 2 Correlation between the expression of DEC1 and clinicopathological factors

\begin{tabular}{|c|c|c|c|c|c|c|}
\hline \multirow{2}{*}{$\begin{array}{l}\text { Clinicopathologic } \\
\text { features }\end{array}$} & \multicolumn{2}{|c|}{ DEC1 protein expression } & \multirow[t]{2}{*}{$P$ value } & \multicolumn{2}{|c|}{ HIF-1a protein expression } & \multirow[t]{2}{*}{$P$ value } \\
\hline & Negative & Positive & & Negative & Positive & \\
\hline Age (yr) & & & 0.108 & & & 0.463 \\
\hline$\leq 50$ & 8 & 23 & & 16 & 15 & \\
\hline$>50$ & 20 & 122 & & 63 & 79 & \\
\hline Sex & & & 0.082 & & & 0.136 \\
\hline Male & 15 & 102 & & 58 & 59 & \\
\hline Female & 13 & 43 & & 21 & 35 & \\
\hline Tumor size (cm) & & & 0.283 & & & 0.920 \\
\hline$\leq 5 \mathrm{~cm}$ & 8 & 57 & & 30 & 35 & \\
\hline$>5 \mathrm{~cm}$ & 20 & 88 & & 49 & 59 & \\
\hline Lymph node metastasis & & & 0.082 & & & 0.000 \\
\hline Yes & 24 & 101 & & 44 & 81 & \\
\hline No & 4 & 44 & & 35 & 13 & \\
\hline TNM stage & & & 0.397 & & & 0.013 \\
\hline$|\sim| \mid$ & 9 & 59 & & 39 & 29 & \\
\hline$\|I\| \sim V$ & 19 & 86 & & 40 & 65 & \\
\hline Tumor differentiation status & & & 0.000 & & & 0.004 \\
\hline Well and moderate & 17 & 36 & & 33 & 20 & \\
\hline Poor & 11 & 109 & & 46 & 74 & \\
\hline
\end{tabular}

histological grade $(\mathrm{P}<0.01$; Table 2 ). DEC1 expression did not differ by tumor size, lymph node metastasis, tumornode-metastasis stage, or age or sex of the patients.

Nuclear expression of HIF- $1 \alpha$ was found in $54.3 \%$ of the tumors, which was significantly higher than that in the adjacent normal tissues $(54.3 \%$ vs $12.7 \%, \mathrm{P}<0.01$, Table 1 , Figure $1 \mathrm{C}$ and $\mathrm{D})$. Furthermore, we also found that the expression of HIF-1 $\alpha$ was correlated with lymph node metastasis, TNM stage and poorly differentiated histological grade $(\mathrm{P}<0.05$, Table 2$)$.

\section{Correlation of DEC1 and HIF-1 1 a expression in human gastric cancer}

To study whether DEC1 is associated with HIF- $1 \alpha$ in gastric cancer, we performed a correlative analysis. The results showed that there is a significant correlation between nuclear or cytoplasmic DEC1 expression and nuclear HIF- $1 \alpha$ expression ( $\mathrm{P}<0.01, \mathrm{r}=0.290$; Table 3 ).

Table 3 Correlation between the expression of DEC1 and HIF-1a

\begin{tabular}{lcccc}
\hline & \multicolumn{2}{c}{ DEC1 expression } & P value & $r$ value \\
\cline { 2 - 4 } & $\begin{array}{c}\text { Positive } \\
(\mathbf{n}=\mathbf{1 4 5})\end{array}$ & $\begin{array}{c}\text { Negative } \\
(\mathbf{n}=\mathbf{2 8})\end{array}$ & & \\
\hline HIF-1a expression & & & $<0.001$ & 0.290 \\
Positive $(n=94)$ & 88 & 6 & & \\
Negative $(n=79)$ & 57 & 22 & & \\
\hline
\end{tabular}

\section{Correlation of DEC1 and Ki67 expression in human gastric} cancer

In all, 56.9\% (98/173) of gastric cancer specimens expressed Ki67 (Figure 1E and F). DEC1 and Ki67 levels were significantly correlated $(\mathrm{P}<0.01, \mathrm{r}=0.249$; Table 4$)$.

\section{Discussion and conclusions}

Previous reports of the implications of DEC1 overexpression in cancer have been inconsistent [10-12], so we investigated gastric cancer specimens from a large consecutive series of gastric cancer patients who had undergone similar surgeries. We extended previous studies by finding a positive correlation between DEC1 and HIF- $1 \alpha$ expression and cancer proliferation.

We found that the DEC1 protein was persistently expressed in both the cytoplasm and the nucleus of gastric cancer. DEC1 was also widely expressed in the cytoplasm of other human tumours, including breast

Table 4 Correlation between the expression of DEC1 and Ki67

\begin{tabular}{lcccc}
\hline & \multicolumn{2}{c}{ DEC1 expression } & P value & $\boldsymbol{r}$ value \\
\cline { 2 - 4 } & $\begin{array}{c}\text { Positive } \\
(\mathbf{n}=\mathbf{1 4 5})\end{array}$ & $\begin{array}{c}\text { Negative } \\
(\mathbf{n}=\mathbf{2 8})\end{array}$ & & \\
\hline Ki67 expression & & & 0.001 & 0.249 \\
Positive $(n=98)$ & 90 & 8 & & \\
Negative $(n=75)$ & 55 & 20 & & \\
\hline
\end{tabular}


cancers, colon/pancreas adenoma, and ductal carcinomas [1]. Only nuclear DEC1 reactivity was found in some clinicopathological studies $[1,13]$. These differences might be explained by the status of the paraffinized sections, subjective interpretation by pathologists, the production of antibodies or the variation in techniques. Although a transcription factor, nuclear DEC1 is likely to be an active form, which is synthesized and degraded in the cytoplasm. Its expression may be redistributed during tissue collection, which would be difficult to control, but the overall expression indicates upregulation of the pathway in gastric cancer. In this study, positive DEC1 staining was found in 145 of 173 (83.8\%) specimens, and nuclear/cytoplasmic DEC1 expression was found to be significantly correlated with nuclear HIF-1 $\alpha$ expression. The analysis based on pure nuclear expression showed very marginal or no statistical association with HIF-1 $\alpha$, showing that strong cytoplasmic DEC1 expression, which is a tumourspecific finding, better reflects the DEC1 regulated pathway in paraffin-embedded material.

HIF- $1 \alpha$ is a well-established molecule induced under hypoxic conditions [14]. As well, DEC1 is inducible by HIF- $1 \alpha$ in various cancer cell lines [5,15-25]. The mechanism of this interaction has been shown to be the HIF- $1 \alpha / \beta$ complex directly binding to the HIF- 1 binding site in the hypoxia response element of the DEC1 promoter, which initiates the transcription of DEC1 $[3,17,26]$. Clinical studies revealed a possible association of HIF- $1 \alpha$ and DEC1 expression by immunohistochemical staining in solid cancers such as non-small lung cancer and breast cancer [1,2]. HIF-1-dependent hypoxia-induced DEC1 expression may be in a hypoxic status in solid cancers. Some studies have shown that the promotion or inhibition of cell differentiation by DEC1 is cell-type specific and differs in different original tissues. Overexpression of Stra13 inhibits mesodermal differentiation but promotes neuronal differentiation in P19 cells [27]. DEC1 was found to be associated with the hypoxic response and high tumour grade in human breast cancers [13]. In hepatocellular carcinoma, the expression of nuclear DEC1 was greater in well differentiated than in poorly differentiated malignant hepatocellular carcinoma [15]. Furthermore, a positive association between tumour grade and HIF-1 $\alpha$ has been reported [28]. These observations suggest that tumor hypoxia can inhibit cancer cell differentiation, and DEC1, induced by HIF- $1 \alpha$, may function as a HIF- $1 \alpha$ effector to mediate the effect of hypoxia on cell differentiation. Thus, DEC1 and HIF- $1 \alpha$ expression is correlated with poor differentiation, as we describe, and is in accordance with the induction by HIF- $1 \alpha$ and the ability of DEC1 to repress tumor differentiation.

Dysregulation of cellular proliferation is a prominent feature of cancers. Ki67 nuclear antigen is a proliferative marker and is a good indicator of the proliferative and differentiation ability of gastric carcinoma cells [29]. DEC1 upregulation encourages the growth of malignant cells by increasing cell proliferation (Figure 2). Cells that lack the functional tumor suppressor von Hippel-Lindau express higher levels of DEC1 [26]. DEC1 is a downstream target of transforming growth factor $\beta$ signaling [17], which promotes the survival of breast cancer cells. Forced expression of DEC1 antagonizes serum deprivation-induced apoptosis and selectively inhibits the activation of procaspases [5]. DEC1 transcriptionally upregulates the expression of the survivin [6] and signal transducer and activator of transcription 3 [30], providing a molecular explanation for DEC1 antiapoptosis. In contrast, DEC1 induces apoptosis in mouse fibroblast NIH3T3 cells, possibly through the regulation of p53 [7]. DEC1 may play a key role in signaling pathways that lead to growth arrest and terminal differentiation by repressing target genes via histone deacetylasedependent and -independent mechanisms [31]. DEC1 overexpression induces the apoptosis of breast cancer MCF-7 cells [8]. DEC1 also acts as a transcriptional repressor to inhibit the transcription of cyclin D1, which is associated with cell proliferation and tumorigenesis [32]. The promotion or inhibition function of DEC1 in cell proliferation may depend on the cell type. In our study, DEC1 positively correlated with the cell proliferation

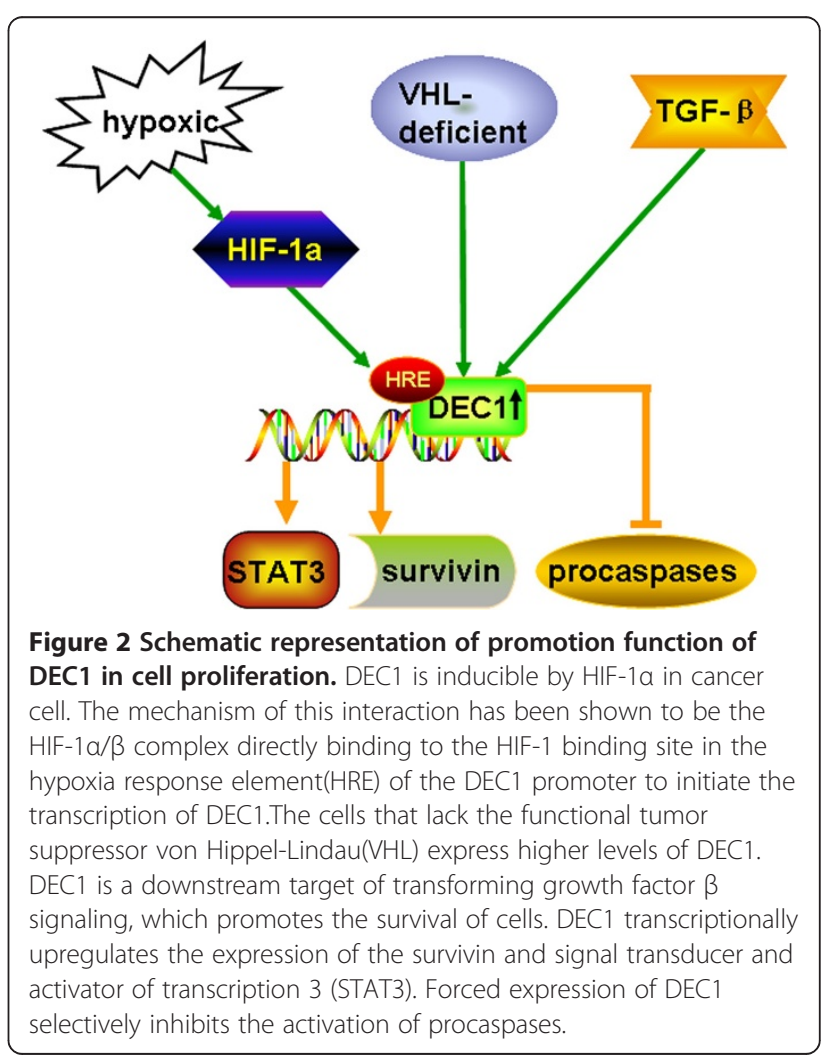


marker Ki67. The increased expression of HIF-1 $\alpha$ DEC1, and Ki67 in poorly differentiated tissues implied that the tumor cells lost growth control in gastric carcinogenesis, thus leading to a DNA synthesis disorder, which reflected the malignant behavior of tumor cells.

In this study, we did not find any association between lymph node metastasis, TNM stage and DEC1 expression, which was in agreement with a study by Chakrabarti J et al. [13] study. Nevertheless, upregulation of DEC1 is strongly associated with HIF-1a and Ki67,previously shown to be associated with aggressive clinical behavior $[9,28,33,34]$, which supports that DEC1 is a marker of activated hypoxic pathways and a novel biomarker of clinical aggressiveness. Although further investigations are needed to clarify the molecular mechanisms involved in DEC1 overexpression, DEC1 may be a valuable therapeutic target in gastric cancer.

\section{Competing interests}

The authors declare that they have no competing interests.

\section{Authors' contributions}

$Y J, Y S, H R, R H$ did the immunohistochemical analysis. YF and $X M$ reviewed all the pathological slides. YJ, DX, YZ, HY, YK analyzed the data. YW designed the study. YJ drafted the manuscript. All authors read and approved the final manuscript.

\section{Acknowledgements}

This work was financially supported by National Natural Science Foundation of China (NSFC No. 81000869 and NSFC No 81272588), 973 Project grant (2012CB966503 and 2012CB966504).

\section{Author details}

'Central Laboratory, Jinan Central Hospital Affiliated to Shandong University, Jinan 250013, Shandong Province, China. ${ }^{2}$ Shandong Province Key Lab of Tumor Target Molecule, Jinan Central Hospital Affiliated to Shandong University, Jinan 250013, Shandong Province, China. ${ }^{3}$ Shandong University School of Medicine, Jinan 250012, Shandong Province, China. ${ }^{4}$ Gynecology and obstetrics, Jinan Central Hospital Affiliated to Shandong University, Jinan 250013, Shandong Province, China.

Received: 9 January 2013 Accepted: 16 February 2013

Published: 27 February 2013

\section{References}

1. Giatromanolaki A, Koukourakis MI, Sivridis E, Turley H, Wykoff CC, Gatter KC, Harris AL: DEC1 (STRA13) protein expression relates to hypoxia- inducible factor 1- $a$ and carbonic anhydrase-9 overexpression in non-small cell lung cancer. J Pathol 2003, 200:222-228.

2. Turley H, Wykoff CC, Troup S, Watson PH, Gatter KC, Harris AL: The hypoxiaregulated transcription factor DEC1 (Stra13, SHARP-2) and its expression in human tissues and tumours. J Pathol 2004, 203:808-813.

3. Miyazaki K, Kawamoto T, Tanimoto K, Nishiyama M, Honda H, Kato Y: Identification of functional hypoxia response elements in the promoter region of the DEC1 and DEC2 genes. J Biol Chem 2002, 277:47014-47021.

4. Zheng Y, Shi X, Wang M, Jia Y, Li B, Zhang Y, Liu Q, Wang Y: The increased expression of DEC1 gene is related to HIF-1a protein in gastric cancer cell lines. Mol Biol Rep 2012, 39:4229-4236.

5. Hu M, Ge S, Yang D, Wan Y, Yan B: Abundant expression of Dec1/stra13/ sharp2 in colon carcinoma: its antagonizing role in serum deprivationinduced apoptosis and selective inhibition of procaspase activation. Biochem J 2002, 367:413-422.

6. Li Y, Xie M, Yang J, Yang D, Deng R, Wan Y, Yan B: The expression of antiapoptotic protein survivin is transcriptionally upregulated by DEC1 primarily through multiple sp1 binding sites in the proximal promoter. Oncogene 2006, 25:3296-3306.
7. Thin TH, Li L, Chung TK, Sun H, Taneja R: Stra13 is induced by genotoxic stress and regulates ionizing-radiation-induced apoptosis. EMBO 2007, 8:401-407.

8. Liu Y, Sato F, Kawamoto T, Fujimoto K, Morohashi S, Akasaka H, Kondo J, Wu Y, Noshiro M, Kato Y, Kijima H: Anti-apoptotic effect of the basic helixloop-helix (bHLH) transcription factor DEC2 in human breast cancer cells. Genes Cells 2010, 15:315-325.

9. Birner P, Schindl M, Obermair A, Plank C, Breitenecker G, Oberhuber G: Overexpression of hypoxia-inducible factorla is a marker for an unfavorable prognosis in earlystage invasive cervical cancer. Cancer Res 2000, 60:4693-4696.

10. Zheng $Y$, Jia $Y$, Wang $Y$, Wang $M$, Li B, Shi X, Ma X, Xiao D, Sun Y: The hypoxia-regulated transcription factor DEC1 (Stra13, SHARP-2) and its expression in gastric cancer. OMICS 2009, 13:301-306.

11. Shi XH, Zheng Y, Sun Q, Cui J, Liu QH, Qü F, Wang YS: DEC1 nuclear expression: a marker of differentiation grade in hepatocellular carcinoma. World I Gastroenterol 2011, 17:2037-2043.

12. Wang W, Reiser-Erkan C, Michalski CW, Raggi MC, Quan L, Yupei Z, Friess H, Erkan M, Kleeff J: Hypoxia inducible BHLHB2 is a novel and independent prognostic marker in pancreatic ductal adenocarcinoma. Biochem Biophys Res Commun 2010, 401:422-428.

13. Chakrabarti J, Turley H, Campo L, Han C, Harris AL, Gatter KC, Fox SB: The transcription factor DEC1 (stra13, SHARP2) is associated with the hypoxic response and high tumour grade in human breast cancers. $\mathrm{Br} J$ Cancer 2004, 91:954-958.

14. Semenza GL: Hypoxia-inducible factor 1: master regulator of $\mathrm{O}_{2}$ homeostasis. Curr Opin Genet 1998, 8:588-594.

15. Wykoff CC, Pugh CW, Maxwell PH, Harris AL, Ratcliffe PJ: Identification of novel hypoxia dependent and independent target genes of the von Hippel-Lindau (VHL) tumour suppressor by mRNA differential expression profiling. Oncogene 2000, 19:6297-6305.

16. Wood SM, Wiesener MS, Yeates KM, Okada N, Pugh CW, Maxwell PH, Ratcliffe PJ: Selection and analysis of a mutant cell line defective in the hypoxia-inducible factor-1a-subunit (HIF-1a). Characterization of hif-1a-dependent and -independent hypoxia-inducible gene expression. J Biol Chem 1998, 273:8360-8368.

17. Zawel L, Yu J, Torrance CJ, Markowitz S, Kinzler KW, Vogelstein B, Zhou S: DEC1 is a downstream target of TGF-beta with sequence-specific transcriptional repressor activities. Proc Natl Acad Sci USA 2002, 99:2848-2853.

18. Li Y, Xie M, Song X, Gragen S, Sachdeva K, Wan Y, Yan B: DEC1 negatively regulates the expression of $D E C 2$ through binding to the E-box in the proximal promoter. J Biol Chem 2003, 278:16899-16907.

19. Li Y, Bi Z, Yan B, Wan Y: UVB radiation induces expression of HIF-1a and VEGF through the EGFR/PI3 K/DEC1 pathway. Int I Mol Med 2006, 18:713-719.

20. Sato F, Bhawal UK, Kawamoto T, Fujimoto K, Imaizumi T, Imanaka T, Kondo J, Koyanagi S, Noshiro M, Yoshida H, Kusumi T, Kato Y, Kijima H: Basic-helixloop-helix (bHLH) transcription factor DEC2 negatively regulates vascular endothelial growth factor expression. Genes Cells 2008, 13:131-144.

21. Nakamura H, Tanimoto K, Hiyama K, Yunokawa M, Kawamoto T, Kato Y, Yoshiga K, Poellinger L, Hiyama E, Nishiyama M: Human mismatch repair gene, $\mathrm{MLH} 1$, is transcriptionally repressed by the hypoxia-inducible transcription factors, DEC1 and DEC2. Oncogene 2008, 27:4200-4209.

22. Qian $Y$, Chen $X: I D 1$, inhibitor of differentiation/DNA binding, is an effector of the p53-dependent DNA damage response pathway. J Biol Chem 2008, 283:22410-22416.

23. Zhang L, Li QQ: Embryo-chondrocyte expressed gene 1, downregulating hypoxia-inducible factor $1 a$, is another marker of lung tumor hypoxia. Acta Pharmacol Sin 2007, 28:549-558.

24. Yoon DY, Buchler P, Saarikoski ST, Hines OJ, Reber HA, Hankinson O: Identification of genes differentially induced by hypoxia in pancreatic cancer cells. Biochem Biophys Res Commun 2001, 288:882-886.

25. Ehata S, Hanyu A, Hayashi M, Aburatani H, Kato Y, Fujime M, Saitoh M, Miyazawa K, Imamura T, Miyazono K: Transforming growth factor-beta promotes survival of mammary carcinoma cells through induction of antiapoptotic transcription factor DEC1. Cancer Res 2007, 67:9694-9703.

26. Ivanova AV, Ivanov SV, Danilkovitch-Miagkova A, Lerman MI: Regulation of STRA13 by the von Hippel-Lindau tumor suppressor protein, hypoxia, and the UBC9/ubiquitin proteasome degradation pathway. J Biol Chem 2001, 276:15306-15315. 
27. Boudjelal M, Taneja R, Matsubara S, Bouillet P, Dolle P, Chambon P: Overexpression of Stra13, a novel retinoic acidinducible gene of the basic helix-loop-helix family, inhibits mesodermal and promotes neuronal differentiation of P19 cells. Genes Dev 1997, 11:2052-2065.

28. Qiu MZ, Han B, Luo HY, Zhou ZW, Wang ZQ, Wang FH, Li YH, Xu RH: Expressions of hypoxia-inducible factor-1a and hexokinase-II in gastric adenocarcinoma: the impact on prognosis and correlation to clinicopathologic features. Tumour Biol 2011, 32:159-166.

29. Wang $L$, Zheng L, Wang SY, Zhu TF, Zhu HG: Clonal analysis of gastric carcinoma and precancerous lesions and its relation to $\mathrm{Ki}-67$ protein expression. Neoplasma 2009, 56:48-55.

30. Ivanova AV, Ivanov SV, Zhang X, Ivanov VN, Timofeeva OA, Lerman MI: STRA13 interacts with STAT3 and modulates transcription of STAT3dependent targets. J Mol Biol 2004, 340:641-653.

31. Sun H, Taneja R: Stra13 expression is associated with growth arrest and represses transcription through histone deacetylase (HDAC)-dependent and HDAC-independent mechanisms. Proc Natl Acad Sci 2000, 97:4058-4063.

32. Bhawal UK, Sato F, Arakawa Y, Fujimoto K, Kawamoto T, Tanimoto K, Ito Y, Sasahira T, Sakurai T, Kobayashi M, Kashima I, Kijima H, Kuniyasu H, Abiko Y, Kato Y, Sato S: Basic helix-loop-helix transcription factor DEC1 negatively regulates cyclin D1. J Pathol 2011, 224:420-429.

33. Cowen D, Troncoso P, Khoo VS, Zagars GK, Von Eschenbach AC, Meistrich ML, Pollack A: Ki-67 staining is an independent correlate of biochemical failure in prostate cancer treated with radiotherapy. Clin Cancer Res 2002, 8:1148-1154.

34. Schmilovitz-Weiss H, Tobar A, Halpern M, Levy I, Shabtai E, Ben-Ari Z: Tissue expression of squamous cellular carcinoma antigen and Ki67 in hepatocellular carcinoma-correlation with prognosis: a historical prospective study. Diagn Pathol 2011, 6:121-129.

doi:10.1186/1746-1596-8-37

Cite this article as: Jia et al:: Differentiated embryonic chondrocyteexpressed gene 1 is associated with hypoxia-inducible factor $1 a$ and Ki67 in human gastric cancer. Diagnostic Pathology 2013 8:37.

\section{Submit your next manuscript to BioMed Central and take full advantage of:}

- Convenient online submission

- Thorough peer review

- No space constraints or color figure charges

- Immediate publication on acceptance

- Inclusion in PubMed, CAS, Scopus and Google Scholar

- Research which is freely available for redistribution 